S E S S Ã O

8 de outubro de 2020

$\infty$

\title{
Árduo Caminho de Desigualdades \\ NA JornAda CONTRA O CÂNCER dE \\ Mama no Brasil
}

"O que devemos fazer na próxima semana que possa nos ajudar a resolver isso?". Com esse questionamento introdutório, o médico Carlos Henrique Barrios, do Hospital da Pontifícia Universidade Católica do Rio Grande do Sul, iniciou sua apresentação na sessão ordinária "Atualização em Câncer de Mama”, da Academia Nacional de Medicina (ANM), que demonstrou que a disparidade de acesso à saúde ainda é um grande empecilho nas estatísticas da doença, sobretudo em países em desenvolvimento, como o Brasil.

Quando outubro marca o mês de conscientização sobre a prevenção e o diagnóstico precoce do câncer de mama, a ANM promoveu, no dia 8, um debate sobre o assunto. Segundo dados do Instituto Nacional do Câncer, este tipo de tumor é o segundo mais comum entre mulheres no país, correspondendo a cerca de $28 \%$ dos novos casos a cada ano. "Existem evidências de que sociedades nas quais cuida-se melhor da saúde feminina apresentam melhores índices de desenvolvimento", comenta Barrios.
No entanto, o especialista afirma que um aumento no número de casos náo simboliza, necessariamente, um aumento na mortalidade. Há uma disparidade evidente e global que se observa em dados - quanto maior o PIB per capita de um país, maior o número de casos e menor a mortalidade, e vice-versa.

Uma explicação possível para este fenômeno pode ser observada no que cerne à indústria farmacêutica. Novos medicamentos trazidos ao mercado são, preferencialmente, distribuídos nos Estados Unidos, que representam $64 \%$ dos contemplados pelas novas drogas, seguidos pelos cinco principais países da Europa (18\%) e pelo Japão (7\%). Em outras palavras, apenas $10 \%$ das novas medicaçóes estão disponíveis para o resto do planeta.

O cenário nacional, por outro lado, náo é uníssono, e apresenta grande desigualdade. A sobrevida para os pacientes com câncer é cada vez maior e a disparidade entre os setores público e privado, nestes aspectos, tem se 
atenuado, exceto no estágio IV (metástase), cuja desigualdade se tornou maior.

Além disso, ainda que a distribuição etária entre pacientes nos sistemas público e privado seja quase idêntica, os estágios dos diagnósticos entre ambos são discrepantes - o que evidencia que o intervalo entre o diagnóstico e o início do tratamento é crucial para a redução da mortalidade e superação da doença, e o Brasil está entre os países que apresentam maior intervalo.

O médico também aponta como a pandemia da covid-19 trouxe grande impacto sobre as estatísticas em câncer. "Devido aos atrasos de diagnósticos e de tratamentos, os poucos meses de pandemia apresentaráo consequências pelos próximos 10 anos".

A sessão contou ainda com a apresentação do médico Benjamin Anderson, da University of Washington, que apresentou as diretrizes estratificadas de recursos e controle global do câncer, analisando, também, cenários das regióes da África e do Caribe. "Não é só o diagnóstico precoce que salva vidas, mas o acesso ao tratamento precoce", ressaltou.

A live da ANM sobre o câncer de mama foi coordenada pelos acadêmicos Maurício Magalhães e Paulo Hoff.
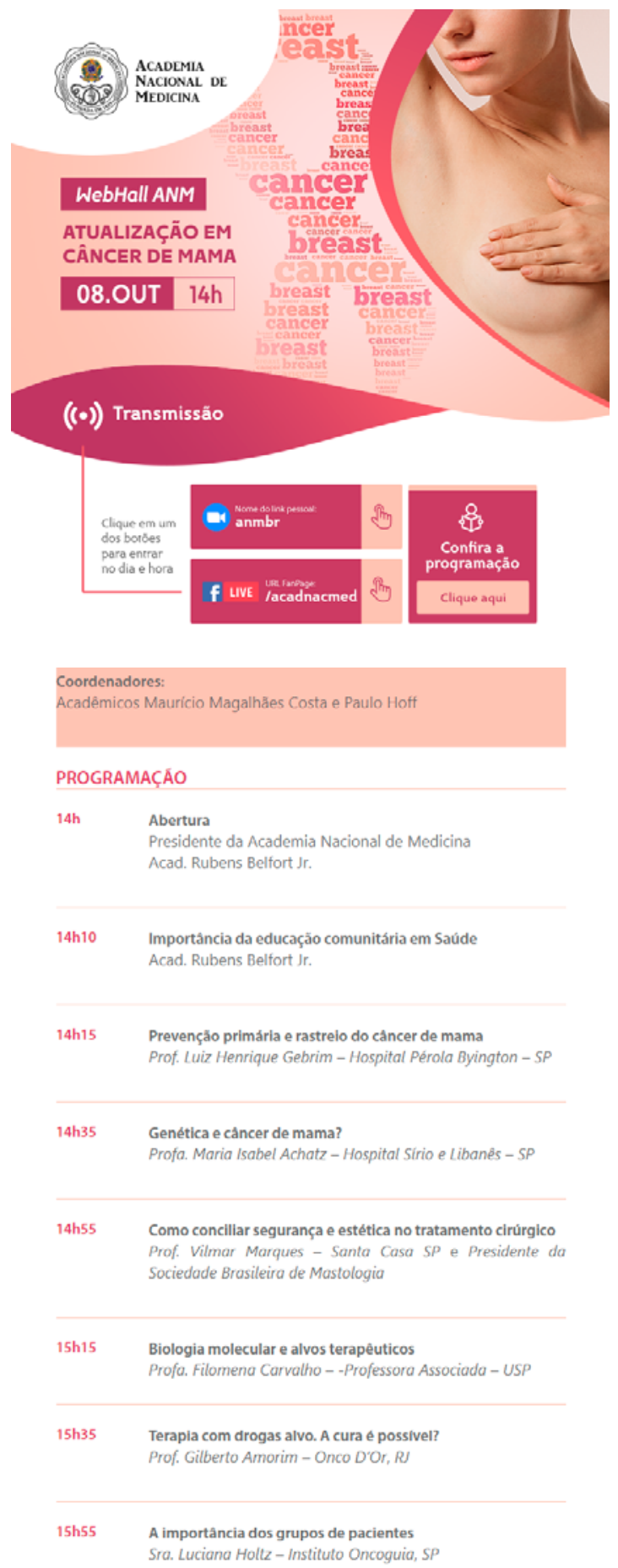
ANAIS $d a$ ACADEMIA NACIONAL DE MEDICINA

Volume 191 (3), 2020

\begin{tabular}{|c|c|}
\hline $16 \mathrm{~h} 15$ & $\begin{array}{l}\text { Debate } \\
\text { Coordenação: Acad. Rubens Belfort Jr. } \\
\text { Acad. José Carlos do Valle } \\
\text { Jornalista Ana Lucia Azevedo - O Globo RJ } \\
\text { Jornalista Natalia Cuminalle - SP }\end{array}$ \\
\hline $17 \mathrm{~h}$ & Discussăo \\
\hline \multirow[t]{2}{*}{$17 \mathrm{~h} 30$} & Intervalo \\
\hline & $\begin{array}{l}\text { Sessão Ordinária da Academia Nacional de Medicina } \\
\text { XXX - Ano Acadêmico } 191\end{array}$ \\
\hline $18 \mathrm{~h}$ & $\begin{array}{l}\text { Abertura } \\
\text { Presidente da Academia Nacional de Medicina } \\
\text { Acad. Rubens Belfort Jr. }\end{array}$ \\
\hline $18 \mathrm{~h} 10$ & $\begin{array}{l}\text { Comunicaçöes da Secretaria Geral } \\
\text { Acad. Ricardo Cruz }\end{array}$ \\
\hline $18 \mathrm{~h} 15$ & Comunicaçōes dos Académicos \\
\hline $18 \mathrm{~h} 30$ & $\begin{array}{l}\text { Desafios na Jornada de pacientes com cancer de mama no } \\
\text { Brasil } \\
\text { Prof. Carlos Henrique Barrios - Hospital PUC-RS e } \\
\text { Oncoclínicas }\end{array}$ \\
\hline $18 \mathrm{~h} 45$ & $\begin{array}{l}\text { Breast Health Global Initiative } \\
\text { Prof. Ben Anderson - World Health Organization }\end{array}$ \\
\hline $19 \mathrm{~h}$ & $\begin{array}{l}\text { Debatedores } \\
\text { Acadêmicos Paulo Hoff e Mauricio Magalhães Costa }\end{array}$ \\
\hline $19 \mathrm{~h} 15$ & Discussáo com a Bancada Academica \\
\hline $20 \mathrm{~h}$ & Encerramento \\
\hline
\end{tabular}

